\title{
Study of deformation microstructure of nickel samples at very short milling times: effects of addition of $\mathrm{a}-\mathrm{Al}_{2} \mathrm{O}_{3}$ particles
}

\author{
Apurba Kanti Deb ${ }^{1} \cdot$ P. Chatterjee ${ }^{2}$
}

Received: 18 May 2018 / Accepted: 16 January 2019 / Published online: 24 January 2019

(c) The Author(s) 2019

\begin{abstract}
Deformation microstructure of pure Ni powder milled for short duration was studied. The microstructure, as obtained on the basis of Rietveld analysis and microstructural modeling, shows inhomogeneity and consists of 'heavily deformed' with twin faults probability and 'slightly deformed' components with varying dislocation densities. The modified Williamson-Hall analysis was performed for both the subcomponents with the relevant scaling parameter. Attempts were made to elucidate the nature of dislocation present in the milled samples. The correction due to extra broadening from stacking fault was calculated from the refined values of twin fault probability. In-depth microstructural modeling with restrictedly random distribution of dislocation and a lognormal distribution of spherical particles were done for the two subcomponents to explore the inhomogeneous microstructure. The effect of $\alpha-\mathrm{Al}_{2} \mathrm{O}_{3}$ addition is found in reduction in the Ni particle size and yielding more uniform size distribution. It is shown that $\mathrm{X}$-ray line profile analysis is capable of modeling such inhomogeneous microstructure.
\end{abstract}

Keywords Co-milled Ni powder $\cdot$ X-ray powder diffraction $\cdot$ Rietveld analysis $\cdot$ Twin fault $\cdot$ Microstructural modeling

\section{Introduction}

It is now well established that mechanical attrition of elemental powder blends of metals, ceramics, etc. provides a route for the production of nano-crystalline materials which may possess unusual chemical and physical properties in comparison to their course-grained counterparts. These materials [1-5] are of tremendous technological importance. During ball milling, a number of processes such as cold welding, fracture, recovery and recrystallization take place and a detailed characterization of all these processes may provide essential information about the nature and property of heavy cyclic deformation. For example, evolution of microstructure of single phase metallic system is characterized by the following stages: (1) The deformation is localized in shear bands - regions of high dislocation density, (2) formation of subgrains as a result of dislocation annihilation, (3) grain rotation to produce a completely random

Apurba Kanti Deb

deb.apurba@gmail.com

1 Department of Physics, Raiganj University, Raiganj, Uttar Dinajpur 733134, India

2 Department of Physics, Vivekananda Mahavidyalaya, Haripal, Hooghly 712405, India orientation. Several authors have observed that for initial hours of milling, there exists microstructural inhomogeneity. A common example of this is the existence of non-unimodal size distribution $[6,7]$. The microstructural inhomogeneity has been attributed to dynamic recrystallization [6], 'undeformed' and 'deformed' components, etc. [7]. We have also observed a similar nature for ball-milled $\alpha-\mathrm{Al}_{2} \mathrm{O}_{3}$, which has been attributed to bimodal distribution of particles of spherical and cylindrical morphology [8].

In the present work, the extent of microstructural inhomogeneity in ball-milled metallic Ni samples co-milled with $\alpha-\mathrm{Al}_{2} \mathrm{O}_{3}$ for short duration of milling is being explored using $\mathrm{X}$-ray diffraction line profile analysis. As the stacking fault energy of $\mathrm{Ni}$ is high, during the course of milling, it is possible that dislocations may localize in some regions. This may result in regions of high dislocation density and some other regions with low dislocation density thereby producing an inhomogeneous microstructure. We propose to separate the dissimilar microstructural fragments as slightly deformed (hereafter referred to as Ni1 subcomponent) and heavily deformed (hereafter referred to as Ni2 subcomponent) using $\mathrm{X}$-ray line profile analysis. The study may elucidate the process of microstructure evolution at very small milling times. 


\section{Experimental}

\section{Sample preparation}

Ceramic material $\alpha-\mathrm{Al}_{2} \mathrm{O}_{3}$ having initial particle size of $\sim 1-2 \mu \mathrm{m}$ has been synthesized by combustion technique from the redox mixture of aluminum nitrate and urea (fuel) with proper stoichiometric composition [9 and the references therein]. Commercially available pure Ni powder $(75 \mu \mathrm{m})$ and prepared $\alpha-\mathrm{AL}_{2} \mathrm{O}_{3}$ were milled in zirconia media (balls and vials) with ball-to-powder ratio of 1:10. Milling was carried out for a short duration $(15 \mathrm{~min})$ in a Fritsch pulverisette planetary mill (P5) operated at $300 \mathrm{rpm}$. Three different samples-pure Ni powder, $\mathrm{Ni}+5 \mathrm{wt} \% \alpha-\mathrm{AL}_{2} \mathrm{O}_{3}$ and $\mathrm{Ni}+10 \mathrm{wt} \% \alpha-\mathrm{AL}_{2} \mathrm{O}_{3}$, were chosen for ball milling.

\section{X-ray diffraction}

The X-ray powder diffraction pattern of the as-prepared samples as well as the standard material (here fully recrystallized Si powder) was taken at room temperature in a PW 1710 diffractometer in a step-scan mode using Ni-filtered $\mathrm{CuK}_{\alpha}$ radiation, operating at $35 \mathrm{kV}$ and $20 \mathrm{~mA}$. A fixed divergence slit of opening $1^{\circ}$ and a receiving slit of opening $0.1 \mathrm{~mm}$ were used for data collection. This slit combination produces a symmetric peak shape with least axial divergence asymmetry effect at low angles. Further, an anti-scatter slit of opening $1^{\circ}$ was also used. The step size was taken to be of $0.02^{\circ} 2 \theta$, and the counting time of $10 \mathrm{~s}$ per step was chosen accordingly to get a good signal-to-noise ratio. Instrumental broadening was corrected using fully recrystallized $\mathrm{Si}$ powder [10].

\section{Results and discussion}

\section{X-ray diffraction and Williamson-Hall plot}

Figure 1 shows the $\mathrm{X}$-ray diffraction pattern of the samples milled for $15 \mathrm{~min}$. Preliminary phase identification confirms the presence of $\mathrm{Ni}$ and $\alpha-\mathrm{Al}_{2} \mathrm{O}_{3}$ in the respective milled samples. It has been shown earlier that for ball-milled ceramic samples $\left(\alpha-\mathrm{Al}_{2} \mathrm{O}_{3}\right)$, the peak shape is super-Lorentzian irrespective of the time employed for milling. The corresponding profile shapes have been attributed purely to crystallite size effects, and a bimodal crystallite size distribution [8] of particles having different crystallite morphologies was observed. However, for ball-milled metallic samples the initial stage of ball milling (as chosen in the present case) is governed by deformation behavior of the metallic particles and associated dislocation motion and/or generation of

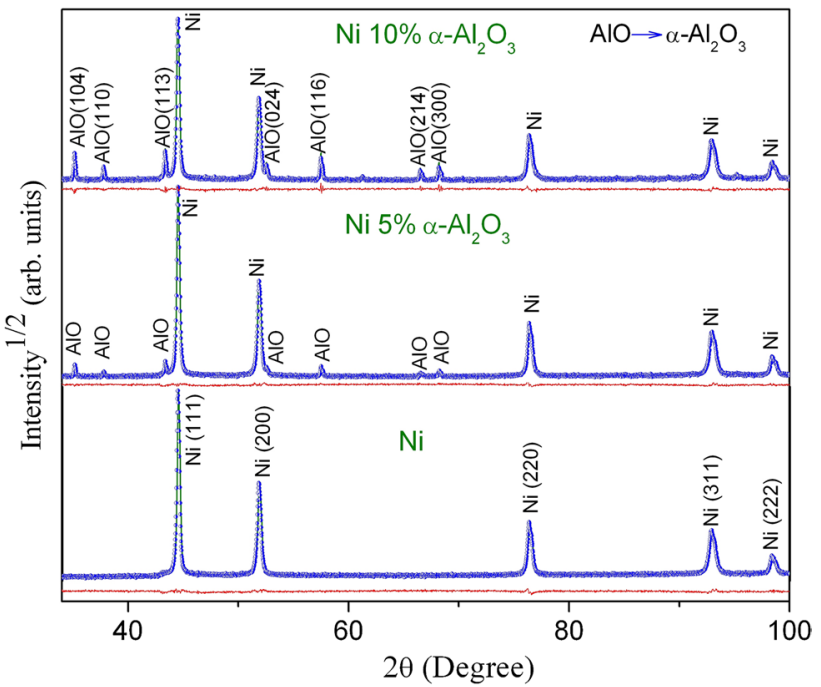

Fig. 1 X-ray diffraction pattern of the ball-milled samples with the fitted pattern by Rietveld method with the residual plot

other defects due to plastic deformation. It has been shown earlier [7] that for ball-milled metallic samples, milled for shorter durations, the sample consists of both deformed and undeformed powder particles. The deformed particles are in the form of thin flakes and give rise to texture effects when loaded into the sample holder. The relative intensities of the $\mathrm{X}$-ray diffraction lines in the present case are in accordance with the literature values, indicating that the texture effect is not prominent in the present case. Further, the time chosen for ball milling is small enough and this should not result in sufficient grain size reduction. Thus, it is presumed in this case that the sample consists of larger particles with sizes probably in the micron range which may have developed a substructure due to plastic deformation.

The individual line profiles were fitted with modified pseudo-Voigt function [11]. Figure 2 shows the Ni 200 and 311 -reflections. It is observed that there is a mismatch in both the peak height and the tail regions. The mismatch is particularly pronounced at higher diffraction angles when a single pseudo-Voigt function is used to fit the diffraction lines. A reasonably good fit is observed when each reflection is fitted with two pseudo-Voigt functions with a constraint on the peak positions. The above feature is present in other $\mathrm{Ni}$ reflections at lower diffraction angles but on a minor scale. The mismatch increases with the increase in the diffraction angle. It is thus evident that the sample can be characterized on the basis of different microstructural fragments present in the sample. It is probable that a non-unimodal distribution may exist either in terms of crystallite size/shape or microstrain at smaller milling times. In the case of ball-milled ceramic $\alpha-\mathrm{Al}_{2} \mathrm{O}_{3}$, the bimodal character has been attributed to crystallite size and shape only [8]. Similar results have earlier been observed by Bor et al. [7] for ball-milled 
Fig. 2 (200) and (311) reflections of $\mathrm{Ni}$ in the three samples fitted with (1) a single modified $\mathrm{pV}$ function (2) modeled with two modified $\mathrm{pV}$ functions

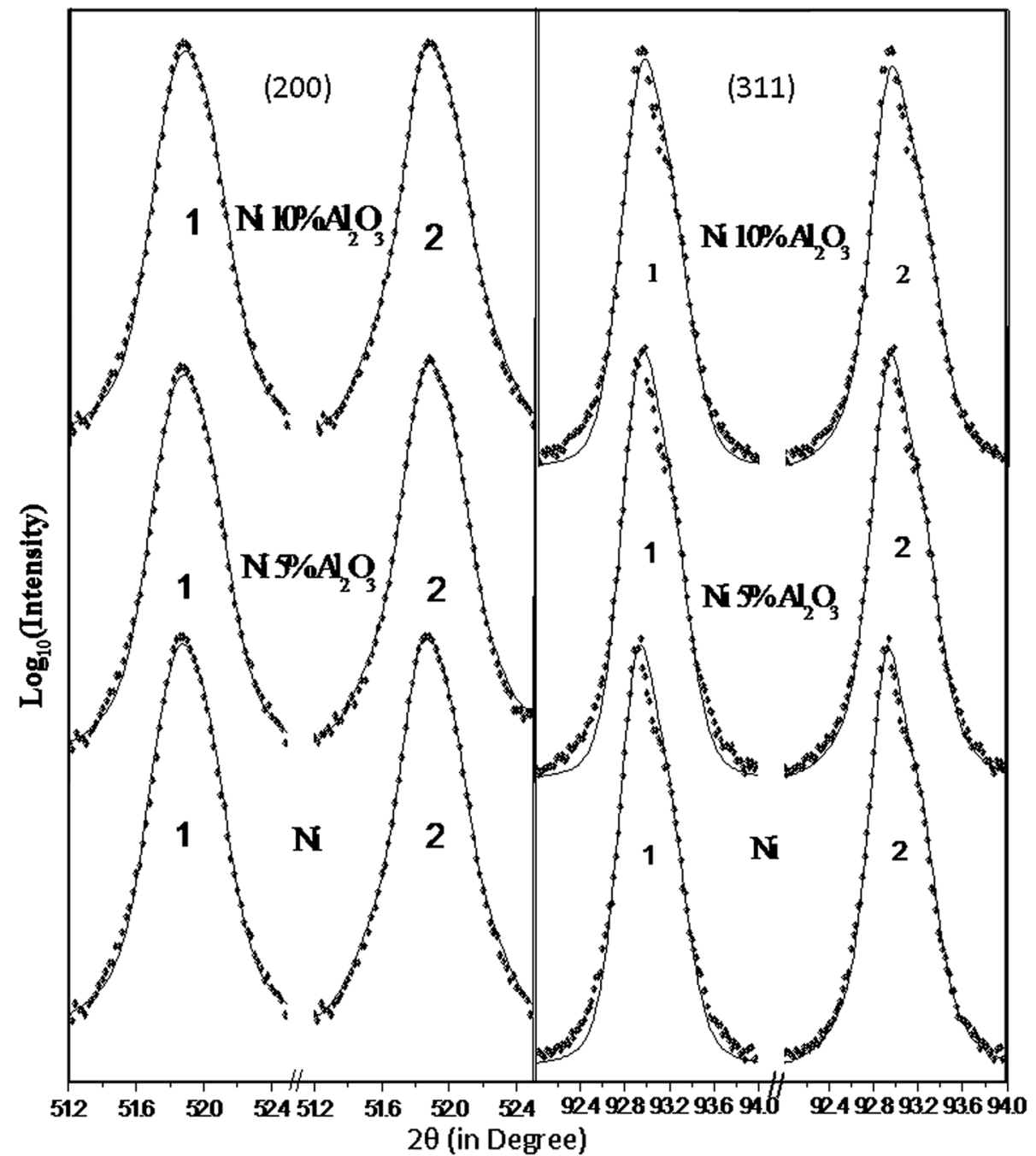

molybdenum sample. They have developed a method for determination of volume fraction of the deformed component in the overall ball-milled sample based on the Fourier transform of the observed profile. In the subsequent section, we have used a modified Rietveld method [12] to explain the nature of microstructurally dissimilar fragments in ballmilled Ni samples.

Figure 3 shows the plot of integral breadth $\beta^{*}$ (in $\sin \theta$ scale) with $d^{*}=(1 / d)$ (conventional Williamson-Hall plot) for the ball-milled $\mathrm{Ni}$ samples with different $\alpha-\mathrm{Al}_{2} \mathrm{O}_{3}$ contents. Each Ni-reflection was fitted with two symmetric subprofiles, and the integral breadths were calculated from the profile parameters. The $\mathrm{W}-\mathrm{H}$ plots are characterized by two general features:

(1) One subcomponent is characterized by nearly isotropic and lesser amount of diffraction line broadening. The broadening is also nearly independent of $\alpha-\mathrm{Al}_{2} \mathrm{O}_{3}$ content in the milled samples. (2) The other subcomponent is characterized by a greater degree of anisotropic diffraction line broadening.
It must be mentioned here that anisotropic line broadening can be in general attributed to either dislocation-induced anisotropic microstrain broadening or anisotropic crystallite size or deformation/twin faults present in the samples. It seems from preliminary analysis that predominant microstrain broadening is present in the samples. The two different subcomponents may be attributed to 'slightly deformed' and 'heavily deformed' components. But, a detailed analysis will reveal the exact cause of anisotropic line broadening observed in the present case.

\section{Rietveld analysis}

Based on the above preliminary analysis, a detailed microstructural characterization has been done on the milled samples using a modified Rietveld method [12]. The 'slightly deformed' and the 'heavily deformed' components designated hereafter as $\mathrm{Ni1}$ and $\mathrm{Ni} 2$ subcomponents, respectively, were separated in the Rietveld analysis by considering two phases of nickel with different microstructural features. Due 


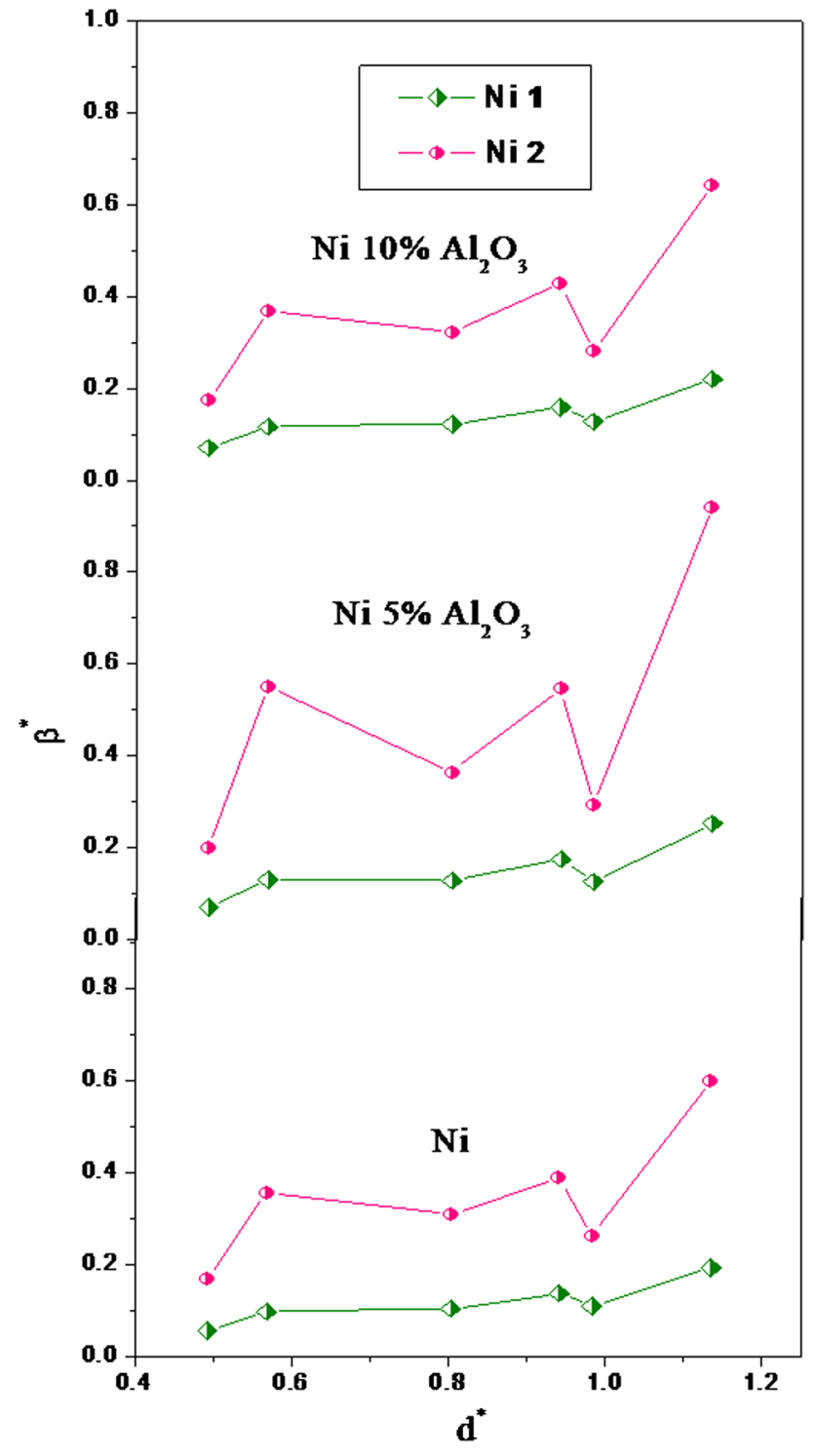

Fig. 3 Williamson-Hall plot of the 'deformed' and 'undeformed' components in all three specimens

to intrinsic overlapping of these two phases, identical cell parameters were assumed for both the microstructurally dissimilar fragments. In the refinement process, only the unit cell parameters, phase and microstructural parameters were refined keeping the structural and thermal parameters fixed. The microstructural refinement was done according to the most general formalism of Popa [13] of anisotropic sizestrain broadening. Stacking/twin faults were included in the refinement process based on Warren's model [14]. The subcomponent $\mathrm{Ni1}$ was refined according to the anisotropic size and microstrain broadening scheme, whereas for the subcomponent $\mathrm{Ni2}$, refinement was carried out with anisotropic size and microstrain broadening scheme along with the presence of twin fault probability $(\beta)$. Figure 1 shows the fitted diffraction pattern and the corresponding residual. Table 1 lists the microstructural parameters such as coherent domain size, r.m.s. microstrain, weight fraction, etc. The weight fraction of $\mathrm{Ni} 2$ subcomponent decreases slightly from $~ 45 \%$ to $\sim 42 \%$ with an increase in the $\alpha-\mathrm{Al}_{2} \mathrm{O}_{3}$ content in the ballmilled samples. It thus appears that the co-milling of $\mathrm{Ni}$ and $\alpha-\mathrm{Al}_{2} \mathrm{O}_{3}$ does not produce substantial change in the weight fraction of the 'heavily deformed' component. The domain or crystallite size of the 'heavily deformed' component $\mathrm{Ni} 2$ is similar for all the samples, whereas the domain size of the 'slightly deformed' component Ni1 decreases with the increase in the $\alpha-\mathrm{Al}_{2} \mathrm{O}_{3}$ content. It is further clear from Table 1 that the crystallite size along $<111>$ and $<100>$ is nearly similar for the Ni1 subcomponent of the milled samples containing $\alpha-\mathrm{Al}_{2} \mathrm{O}_{3}$, but slight anisotropy exists for the samples milled without $\alpha-\mathrm{Al}_{2} \mathrm{O}_{3}$. It is thus clear that the harder $\alpha-\mathrm{Al}_{2} \mathrm{O}_{3}$ particles have a greater effect on size reduction during the milling process and introduction of $\alpha-\mathrm{Al}_{2} \mathrm{O}_{3}$ in the milling media results in grain refinement. The $\mathrm{Ni2}$ subcomponent reveals domain size anisotropy. This anisotropy may be associated with anisotropic domain size and/or deformation/twin faults. It further seems that the microstructure of $\mathrm{Ni} 2$ subcomponent is independent of the $\alpha-\mathrm{Al}_{2} \mathrm{O}_{3}$ content in the milled samples, and it may be characteristic of ball-milled metallic samples. The two subcomponents $\mathrm{Ni1}$ and Ni2 differ significantly in the r.m.s. microstrain values. However, the microstrain values are independent of the $\alpha-\mathrm{Al}_{2} \mathrm{O}_{3}$ content in either case. It is further noted that the $\mathrm{Ni} 2$ subcomponent is characterized by a twin fault probability $(\beta)$ of $\sim 0.1 \%$, and it is independent of the $\alpha-\mathrm{Al}_{2} \mathrm{O}_{3}$ content in the co-milled samples. The refined value of deformation stacking fault probability $\alpha$ was small negative indicating complete absence of deformation stacking faults and is a characteristic of materials with high stacking fault energy such as Ni. The occurrence of twin fault in ball-milled samples is widespread and has been observed earlier in $\mathrm{Ti}$ [15], $\mathrm{Ni}$ [16], etc. The value of $\beta$ indicates that every one plane out of 100 planes is faulted. It must be noted that the crystallite size/coherent domain size values quoted in Table 1 are effective crystallite size, which includes the effect of faulting and not the true crystallite size. The effective crystallite size $D_{\text {eff }}$ for the Ni1 subcomponent ranges from 72 to $110 \mathrm{~nm}$ for the two crystallographic directions [111] and [100], whereas it is between 19 and $30 \mathrm{~nm}$ for the Ni2 subcomponents depending on the alumina content in the milled samples.

If it is assumed that the microstrain present in the samples is due to dislocations, the average formal dislocation density can be calculated according to the Williamson-Smallman relations as described in Ref [17]. The dislocation density is of the order of $10^{15} / \mathrm{m}^{2}$. Further, it is noted that the dislocation density differs by nearly one order magnitude for the Ni1 and Ni2 subcomponent which supports the proposition of heavily deformed and slightly deformed specimen. 
Table 1 Results of Rietveld analysis for the ball-milled $\mathrm{Ni}$ samples

\begin{tabular}{|c|c|c|c|c|c|c|}
\hline & \multicolumn{2}{|c|}{$\mathrm{Ni}-0 \mathrm{wt} \% \mathrm{Al}_{2} \mathrm{O}_{3}$} & \multicolumn{2}{|c|}{$\mathrm{Ni}-5 \mathrm{wt} \% \mathrm{Al}_{2} \mathrm{O}_{3}$} & \multicolumn{2}{|c|}{$\mathrm{Ni}-10 \mathrm{wt} \% \mathrm{Al}_{2} \mathrm{O}_{3}$} \\
\hline & Ni1 & $\mathrm{Ni} 2$ & Ni1 & $\mathrm{Ni} 2$ & Ni1 & $\mathrm{Ni} 2$ \\
\hline Relative wt & 54.8 & 45.2 & 61.1 & 38.9 & 57.8 & 42.2 \\
\hline$a(\AA)$ & 3.526 & & 3.526 & & 3.525 & \\
\hline \multicolumn{7}{|l|}{$D_{\text {eff }}(\mathrm{nm})$} \\
\hline$<111>$ & 110 & 28 & 95 & 29 & 78 & 30 \\
\hline $\begin{array}{l}<200> \\
<\mathrm{e}^{2}>^{1 / 2}\left(\times 10^{3}\right)\end{array}$ & 81 & 19 & 93 & 18 & 72 & 19 \\
\hline$<111>$ & 1.72 & 2.92 & 1.63 & 3.25 & 1.78 & 3.05 \\
\hline$<200>$ & 2.25 & 5.81 & 2.56 & 6.39 & 2.46 & 5.76 \\
\hline Twin fault $(\beta)$ & 0.0 & 0.011 & 0.0 & 0.012 & 0.0 & 0.012 \\
\hline$\rho<\operatorname{avg}>\left(\times 10^{-15} \mathrm{~m}^{-2}\right)$ & 0.65 & 6.2 & 0.66 & 7.0 & 0.86 & 6.1 \\
\hline $\mathrm{R}_{\mathrm{wp}}$ & 3.207 & & 3.191 & & 3.70 & \\
\hline Gof & 1.262 & & 1.278 & & 1.382 & \\
\hline
\end{tabular}

A detailed analysis of the validity of the assumption was performed, and the character and arrangement of the dislocation are shown in the subsequent sections.

\section{Modified Williamson-Hall analysis}

In order to understand the origin of anisotropic strain broadening and test the validity of the assumption made in the previous section, it is essential to perform the modified Williamson-Hall analysis as proposed by Ungar et al. [18]. The anisotropy observed in the broadening of the diffraction lines is partly due to geometrical factors such as the orientation of the burgers vector and the dislocation line vector and partly due to anisotropic elastic constants. In the present analysis, it is considered that all the slip systems are equally populated so that we can use the average contrast factor for the dislocations. In order to rationalize the anisotropy of integral breadths observed in conventional W-H plot, modified $\mathrm{W}-\mathrm{H}$ analysis was performed for both the $\mathrm{Ni1}$ and Ni2 subcomponents. The average contrast factor of dislocation for each $h k l$ reflection is given according to the relation $\bar{C}_{h k l}=\bar{C}_{h 00}\left(1-q H^{2}\right)[19-21]$ where $C_{h k l}$ is the dislocation contrast factor for $h \mathrm{kl}$ reflection and $C_{h 00}$ is the corresponding dislocation contrast factor for $h 00$-type reflection and $H^{2}=\left(h^{2} k^{2}+h^{2} l^{2}+k^{2} l^{2}\right) /\left(h^{2}+k^{2}+l^{2}\right)^{2}$.

A preliminary indication of the type of dislocation present in the sample can be found by determining the parameter ' $q$ ' from the plot of $\left\{\beta^{*} / d^{*}\right\}^{2}$ with $H^{2}$. Figure $4 \mathrm{a}$ and $\mathrm{b}$ shows such a plot for milled pure $\mathrm{Ni}$ samples. The experimental q values are 1.70 and 2.21 for the $\mathrm{Ni1}$ and $\mathrm{Ni2}$ phases, respectively. The theoretical values of q calculated for edge and screw dislocations in $\mathrm{Ni}$ are 1.38 and 2.23, respectively.

The values of $q$ as obtained indicate that type of dislocation in the pure-milled Ni sample is approximately of $50 \%$
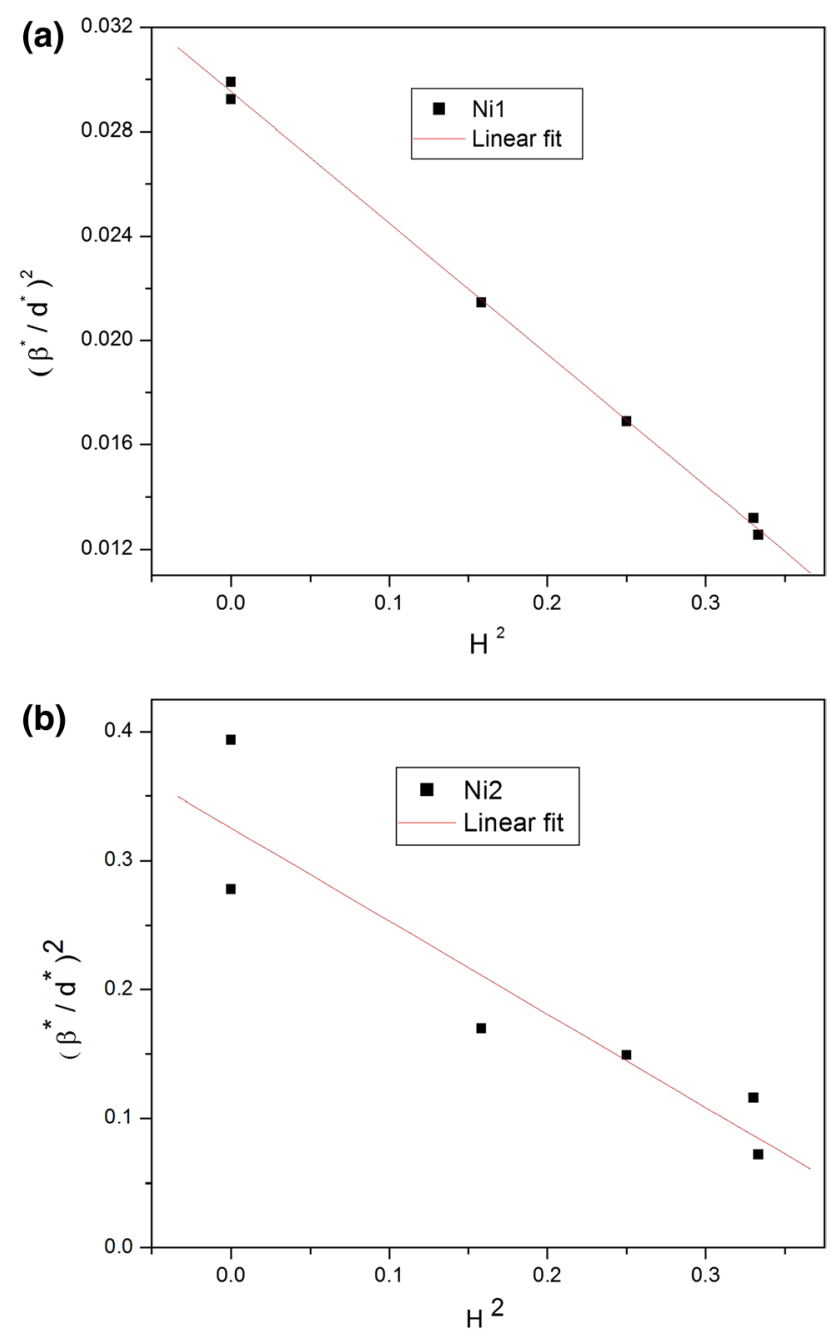

Fig. 4 Plot of $\left\{\beta^{*} / d^{*}\right\}^{2}$ with $H^{2}$ for determination of dislocation type factor q for pure ball-milled $\mathrm{Ni}$, a $\mathrm{Ni1} \mathbf{b} \mathrm{Ni} 2$ 
edge and 50\% screw character, for the Ni1 subcomponent, whereas it is mostly screw type for the Ni2 subcomponent [19-21].

The modified Williamson-Hall analysis was performed for both the Ni1 and Ni2 subcomponents with the scaling parameter of $K^{2} \bar{C}$. The correction of integral breadths due to extra broadening originating from stacking fault [19] for Ni2 subcomponent was carried out using the refined values of twin fault probability obtained from earlier analysis. Figure 5 shows the modified Williamson-Hall plot for both the Ni subcomponents. The plot follows a smooth quadratic behavior with the new scaling parameter $K^{2} \bar{C}$. This behavior is consistent with dislocation-induced anisotropic $\mathrm{X}$-ray line broadening as noted by several authors. Isotropic-volume-averaged crystallite size for both the samples is obtained from the plot, and the values are $\left\langle L_{V}\right\rangle=148 \mathrm{~nm}$ for Ni1 subcomponent and $\left\langle L_{V}\right\rangle=39 \mathrm{~nm}$ for Ni2 subcomponent. Modified Williamson-Hall analysis
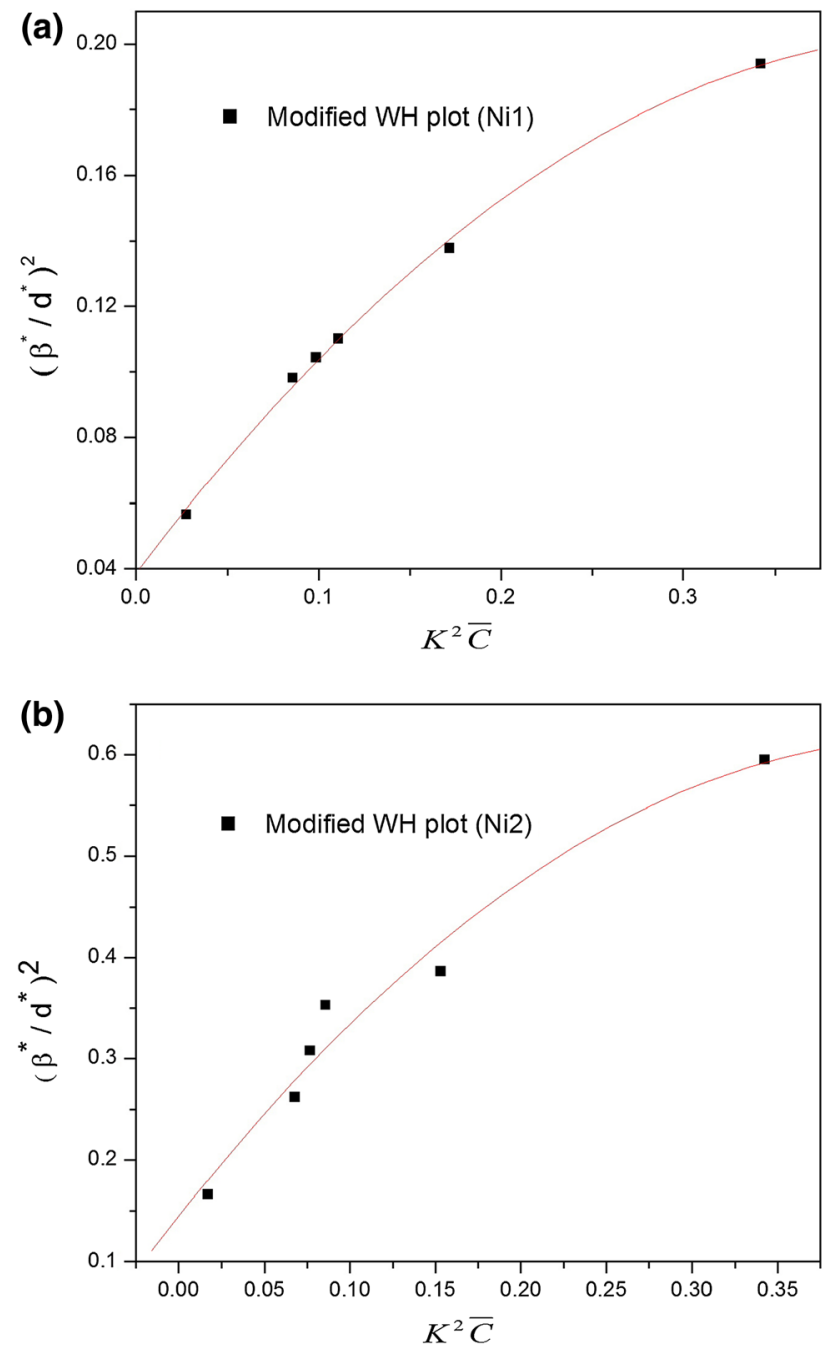

Fig. 5 Modified Williamson-Hall plot for pure Ni specimen a Ni1 b $\mathrm{Ni} 2$ does not provide reliable values for the dislocation density. A more detailed analysis is presented in the next section to elucidate that shortcoming.

\section{Microstructural modeling}

It is clear from the discussion in earlier section that for initial milling hours, deformation occurs due to dislocation motion and eventually an inhomogeneous dislocation microstructure results. Such a dislocation motion produces local variation of dislocation density. To estimate the dislocation microstructure of the co-milled $\mathrm{Ni}-\alpha-\mathrm{Al}_{2} \mathrm{O}_{3}$ specimen, it is essential to perform an analysis of the $\mathrm{Ni1}$ and $\mathrm{Ni} 2$ subcomponents on the basis of a microstructural model. In the present study, a restrictedly random dislocation distribution and a lognormal distribution of the spherical particles have been considered $[22,23]$. It has been showed by several authors that the Wilkens model is perhaps the best model till date to explain dislocation-induced line broadening from deformed metals and alloys.

For the microstructural model assumed in the present analysis, the physical normalized Fourier transform for several reflections is fitted simultaneously by the normalized theoretical Fourier transform. The Fourier transform for a dislocated spherical crystallite with a log normal size distribution is expressed as [24]:

$A(L)=\frac{A_{\mathrm{s}}(L)}{A_{0}^{\mathrm{s}}} \exp \left\{-\left(\frac{\pi b^{2}}{2}\right) \rho L^{2} f\left(\frac{L}{R_{\mathrm{e}}^{*}}\right) K^{2} \bar{C}\right\}$

where $L$ is the Fourier variable, $b$ is the Burger's vector, $\rho$ is the dislocation density and $R_{\mathrm{e}}^{*}$ is the effective outer cutoff radius of dislocation distribution and $A_{\mathrm{s}}(L)$ is the size Fourier coefficient for a lognormal distribution of spherical crystallites.

The size Fourier coefficient $A_{\mathrm{S}}(L)$ is expressed in a closed form as

$$
\begin{aligned}
A_{\mathrm{S}}(L)= & \frac{D_{0}^{3} \exp \left(\frac{9}{2} \sigma^{2}\right)}{3} \operatorname{erfc}\left[\frac{\log \left(|L| / D_{0}\right)}{\sqrt{2} \sigma}-\frac{3}{2} \sqrt{2} \sigma\right] \\
& -\frac{D_{0}^{2} \exp \left(2 \sigma^{2}\right)}{2}|L| \operatorname{erfc}\left[\frac{\log \left(|L| / D_{0}\right)}{\sqrt{2} \sigma}-\sqrt{2} \sigma\right] \\
& +\frac{|L|^{3}}{6} \operatorname{erf}\left[\frac{\log \left(|L| / D_{0}\right)}{\sqrt{2} \sigma}\right]
\end{aligned}
$$

where $D_{0}$ is the median size and $\sigma^{2}$ is the variance of the size distribution.

In the present analysis, pseudo-Voigt function is used to decompose the subprofiles corresponding to the Ni1 and Ni2 subcomponents. The Fourier transforms of such subprofiles are obtained from the relation 
$A(L)=Z /(1+Z) \exp \left[-\pi^{2} w^{2} L^{2} / \ln 2\right]+1 /(1+Z) \exp [-2 \pi w L]$

where $Z=(\pi / \ln 2)^{1 / 2} \eta /(1-\eta)$ and $w=(2 / \lambda)\left[\sin \left(\theta_{0}+\right.\right.$ HWHM) $\left.-\sin \theta_{0}\right] . \eta$ is the Gaussian content of the $\mathrm{pV}$ function, $\theta_{0}$ being the Bragg angle and $\lambda$ is the wavelength of the $\mathrm{X}$-ray used. For Ni2 subcomponent, the correction for extra broadening due to twin faults $(\beta)$ has been done according to [19]

$$
\begin{aligned}
\ln A(L)+L \beta^{\prime} W(g)= & -\left(L / D_{A}\right)-\rho\left(\pi b^{2} / 2\right) L^{2} \ln \left(R_{\mathrm{e}} / L\right) \\
& \left(K^{2} \bar{C}\right)+O\left(K^{2} \bar{C}\right)^{4}
\end{aligned}
$$

with $\beta^{\prime}=(1.5 \alpha+\beta) / a$. Here, $\beta$ and $\alpha$ are the twin boundary and deformation stacking fault probabilities, $a$ is the lattice constant and $W(g)$ is a variable whose value depends on the crystallographic system and on Miller indices of the reflection.

The resultant Fourier coefficients for the first six reflections, viz-111, 200, 220, 311, 222 and 400, were fitted simultaneously with the theoretical Fourier transforms by using the software MWP [25]. Initially, average contrast factors $\left(\bar{C}_{h 00}\right)$, for most common dislocation slip systems in fcc nickel $\left(\bar{C}_{h 00 \text { edge }}=0.2622, \bar{C}_{h 00 \text { screw }}=0.2635\right)$, were estimated by using the software ANIZC [26]. During the fitting procedure, the average contrast factor and the Burgers vector $(b=a / \sqrt{2})$ were supplied as non-refinable input parameters. The program refines the parameters such as dislocation density $(\rho)$, effective outer cutoff radius of dislocation $\left(R_{\mathrm{e}}^{*}\right)$, the median $\left(D_{0}\right)$ and variance $\left(\sigma^{2}\right)$ of the lognormal size distribution. Best fitting results were obtained for the spherical crystallite model in all cases.

Figure $6 \mathrm{a}$ and $\mathrm{b}$ shows the fitting results. Table 2 lists the microstructural parameters, viz., median and variance of the size distribution. The dislocation distribution is characterized by dislocation density $(\rho)$, dislocation type factor $(q)$, dislocation arrangement $(M)$, etc. Table 2 also lists the average area and volume weighted domain sizes, $\left\langle L_{A}\right\rangle$ and $<L_{V}>$, respectively. It is observed from Table 2 that the Ni2 subcomponent is characterized by slightly higher dislocation density $\left(\sim 5-6 \times 10^{15} \mathrm{~m}^{-2}\right)$ and very narrow size distribution, and it is independent of the $\alpha-\mathrm{Al}_{2} \mathrm{O}_{3}$ content in the ball-milled samples. The dislocation arrangement is nearly random. The anisotropic X-ray line broadening observed in Fig. 3 can thus be rationalized on the basis of anisotropic dislocation contrast and twin faults. The dislocations are of mixed character with nearly equal contributions from edge and screw types. For the Ni1 subcomponent, a definite effect of $\alpha-\mathrm{Al}_{2} \mathrm{O}_{3}$ on the size reduction is evident. Although the median $(m)$ of the size distribution increases, the areaweighted domain size decreases with the increase in $\alpha-\mathrm{Al}_{2} \mathrm{O}_{3}$ content in the co-milled samples. The variance $\sigma^{2}$ of the size distribution also decreases indicating a narrow grain size distribution. Figure $7 \mathrm{a}$ and $\mathrm{b}$ shows the grain size distribution according to the expression

$$
G(D)=\frac{1}{\sigma \sqrt{2 \pi}} \frac{1}{D} \exp \left[-\frac{\left[\ln \frac{D}{D_{0}}\right]^{2}}{2 \sigma^{2}}\right]
$$

The dislocation density for the Ni1 subcomponent is slightly less $\left(\sim 3.5 \times 10^{15} \mathrm{~m}^{-2}\right)$. The dislocation arrangement is nearly random, as the value of dislocation arrangement parameter $M$ is nearly equal to unity. It is thus clear that for ball-milled metallic samples, milled for smaller times, an inhomogeneous microstructure exists from the very beginning and is characterized by different dislocation microstructures. Addition of the harder particles during milling has a definite effect on size reduction and produces a narrower and uniform size distribution.

\section{Scanning electron microscopy analysis}

The morphology of the shortly milled pure Ni sample was investigated by scanning electron microscopy (SEM). Figure 8 shows the SEM image of the Ni sample milled for $15 \mathrm{~min}$. From the micrograph, it is observed that the particles are dissimilar in size and shape. The grains appeared to be deformed. On visual inspection, on average, particles having two different sizes are observed in the SEM micrograph. However, due to agglomeration and irregularity in shape, no attempts were made to obtain the size distribution from the SEM image.

\section{Conclusion}

Co-milling of $\mathrm{Ni}$ and $\alpha-\mathrm{Al}_{2} \mathrm{O}_{3}$ for small milling times (15 min) was studied on the basis of Rietveld analysis and microstructural modeling based on restrictedly random dislocation distribution and spherical lognormal crystallite size distribution. The microstructure consists of 'heavily deformed' and 'slightly deformed' fragments. The volume fraction of the 'heavily deformed' component varies in between 42 and $45 \%$ and is independent of the harder $\alpha-\mathrm{Al}_{2} \mathrm{O}_{3}$ particles. Both the fragments are characterized by nearly random dislocation microstructure. The "heavily deformed' component is characterized by high twin faults probability $\beta \sim 0.01$. $\alpha-\mathrm{Al}_{2} \mathrm{O}_{3}$ particles have a definite effect on the size reduction in the Ni particles. More uniform size distribution could be observed with increasing $\alpha-\mathrm{Al}_{2} \mathrm{O}_{3}$ in the co-milled samples. 

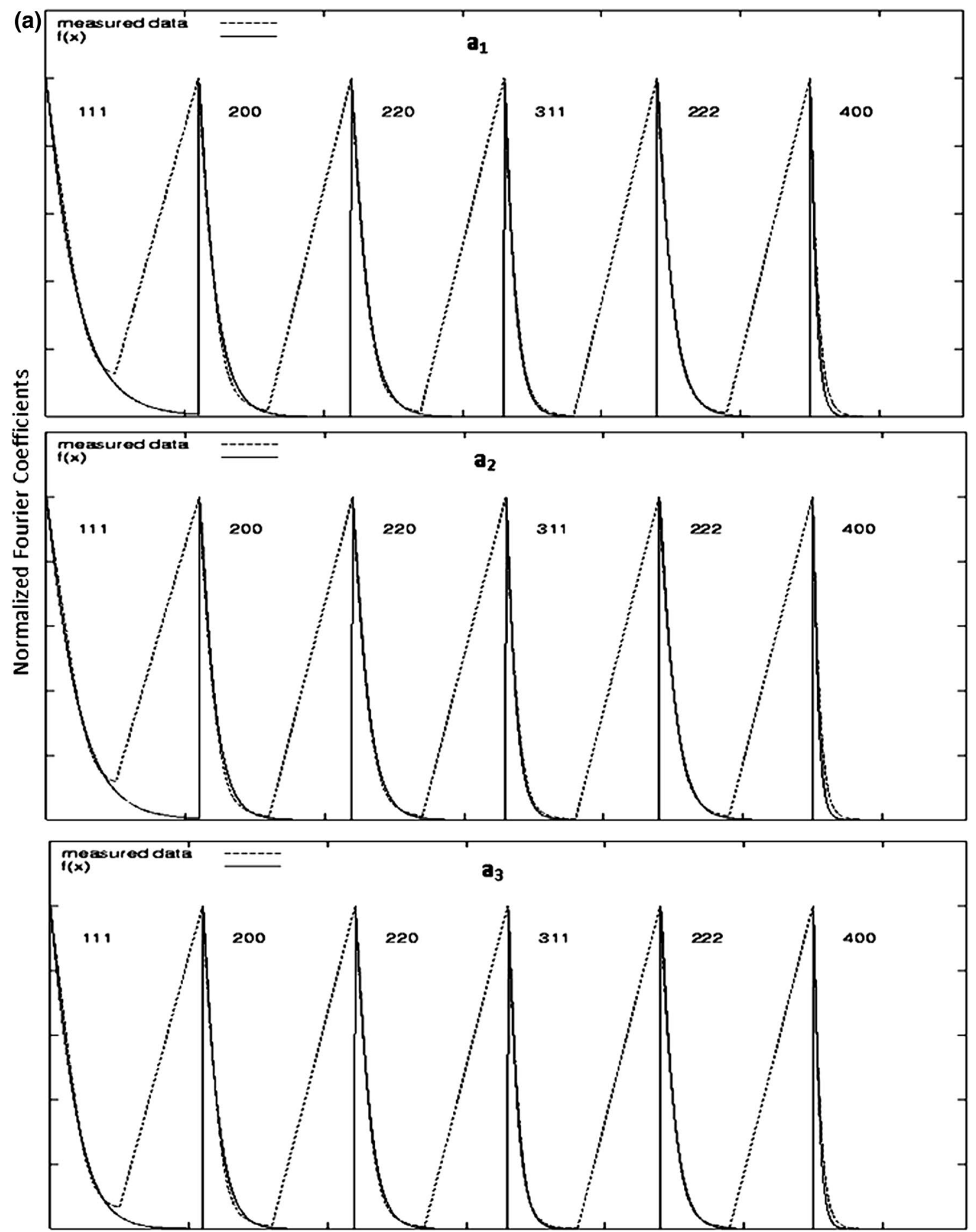

Fig. 6 a Multiple whole profile fitting of normalized Fourier transforms for Ni1 subcomponent in $\left(a_{1}\right) \mathrm{Ni}-0 \% \alpha-\mathrm{Al}_{2} \mathrm{O}_{3}\left(\mathrm{a}_{2}\right) \mathrm{Ni}-5 \% \alpha-$ $\mathrm{Al}_{2} \mathrm{O}_{3}\left(\mathrm{a}_{3}\right) \mathrm{Ni}-10 \% \alpha-\mathrm{Al}_{2} \mathrm{O}_{3}$ composites. b Multiple whole profile fit- ting of normalized Fourier transforms for Ni2 subcomponent in $\left(b_{1}\right)$ $\mathrm{Ni}-0 \% \alpha-\mathrm{Al}_{2} \mathrm{O}_{3}\left(\mathrm{~b}_{2}\right) \mathrm{Ni}-5 \% \alpha-\mathrm{Al}_{2} \mathrm{O}_{3}\left(\mathrm{~b}_{3}\right) \mathrm{Ni}-10 \% \alpha-\mathrm{Al}_{2} \mathrm{O}_{3}$ composites 

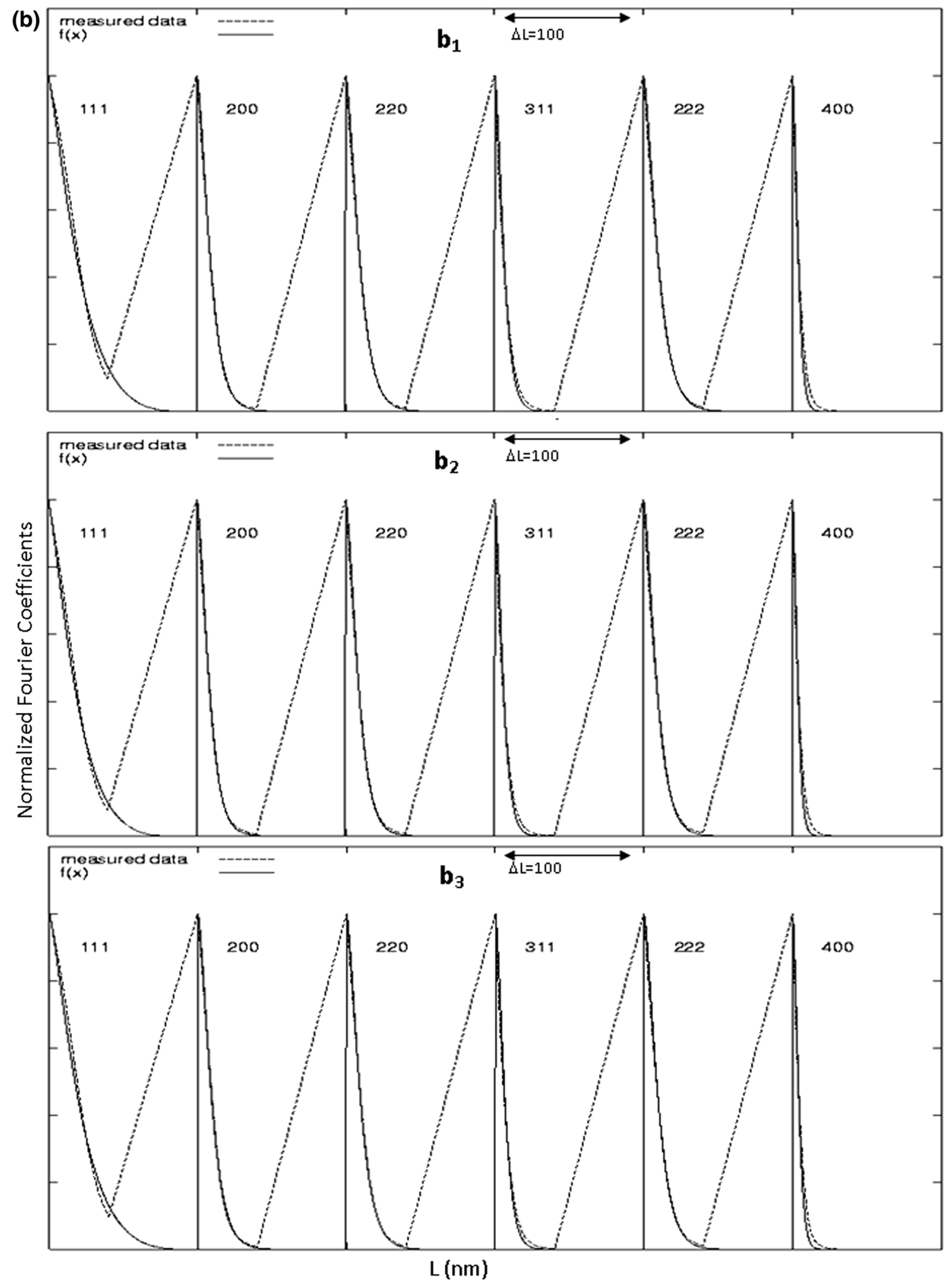

Fig. 6 (continued) 
Table 2 Microstructural parameters for the multiple whole profile fitting by Fourier coefficient of theoretical size and strain profiles

\begin{tabular}{|c|c|c|c|c|c|c|}
\hline & \multicolumn{2}{|c|}{$\mathrm{Ni}-0 \mathrm{wt} \% \mathrm{Al}_{2} \mathrm{O}_{3}$} & \multicolumn{2}{|c|}{$\mathrm{Ni}-5 \mathrm{wt} \% \mathrm{Al}_{2} \mathrm{O}_{3}$} & \multicolumn{2}{|c|}{$\mathrm{Ni}-10 \mathrm{wt} \% \mathrm{Al}_{2} \mathrm{O}_{3}$} \\
\hline & Ni1 & $\mathrm{Ni2}$ & Ni1 & $\mathrm{Ni2}$ & Ni1 & $\mathrm{Ni2}$ \\
\hline$D_{0}(\mathrm{~nm})$ & 48 & 88 & 66 & 81 & 70 & 91 \\
\hline$\sigma$ & 0.64 & $\sim 0.0$ & 0.54 & $\sim 0.0$ & 0.42 & $\sim 0.0$ \\
\hline$<L_{A}>(\mathrm{nm})$ & 89 & 58 & 91 & 54 & 73 & 60 \\
\hline$<L_{V}>(\mathrm{nm})$ & 150 & 65 & 137 & 61 & 99 & 68 \\
\hline$q$ & 1.77 & 2.15 & 1.99 & 2.14 & 1.76 & 2.05 \\
\hline$\rho\left(10^{15} \mathrm{~m}^{-2}\right)$ & 3.5 & 5.0 & 3.6 & 5.8 & 3.5 & 4.8 \\
\hline$M$ & 1.0 & 2.3 & 1.26 & 2.3 & 1.25 & 2.3 \\
\hline
\end{tabular}
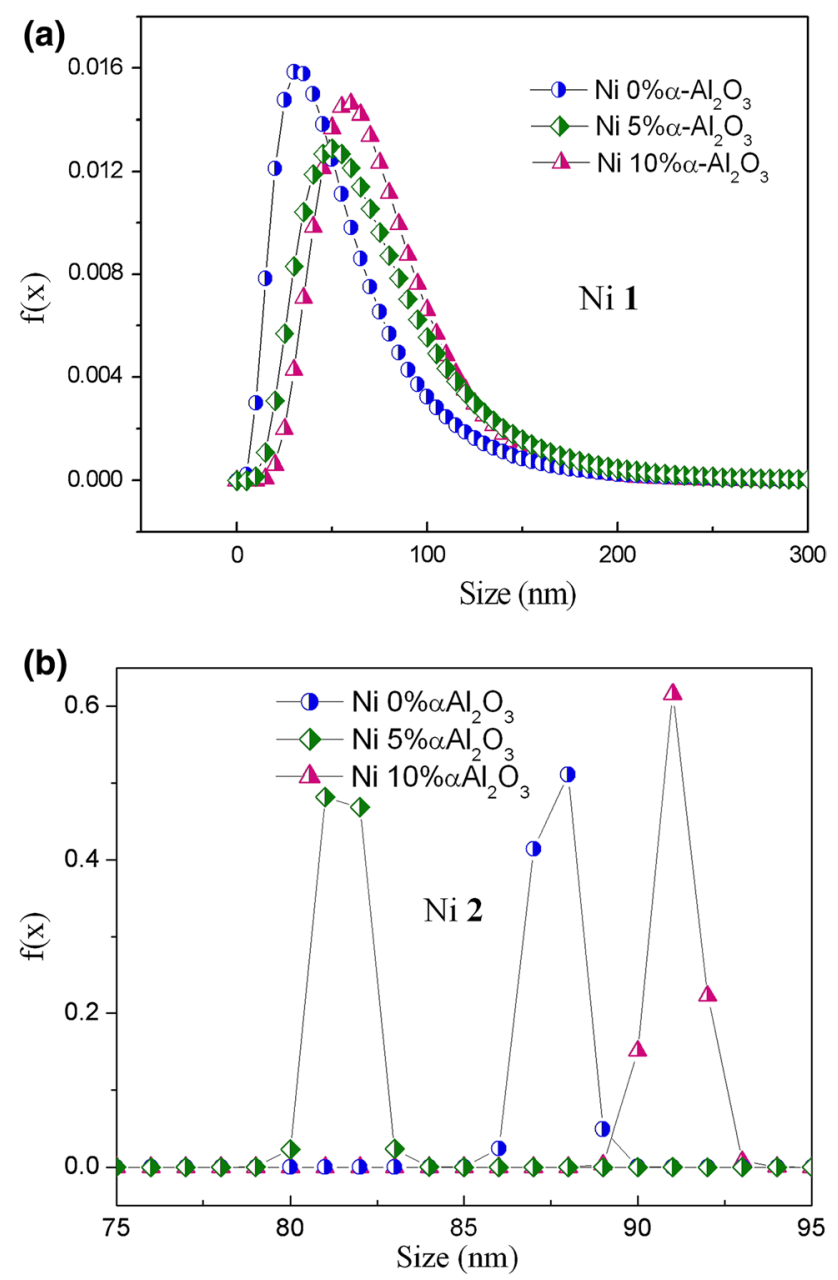

Fig. 7 a Grain size distribution of Ni1 subcomponent. b Grain size distribution of $\mathrm{Ni2}$ subcomponent

It is thus clear that addition of $\alpha-\mathrm{Al}_{2} \mathrm{O}_{3}$ during milling of $\mathrm{Ni}$ may result in a more uniform deformed microstructure than that compared to Ni only. However, efforts are being made to study higher milling times to study the effects of

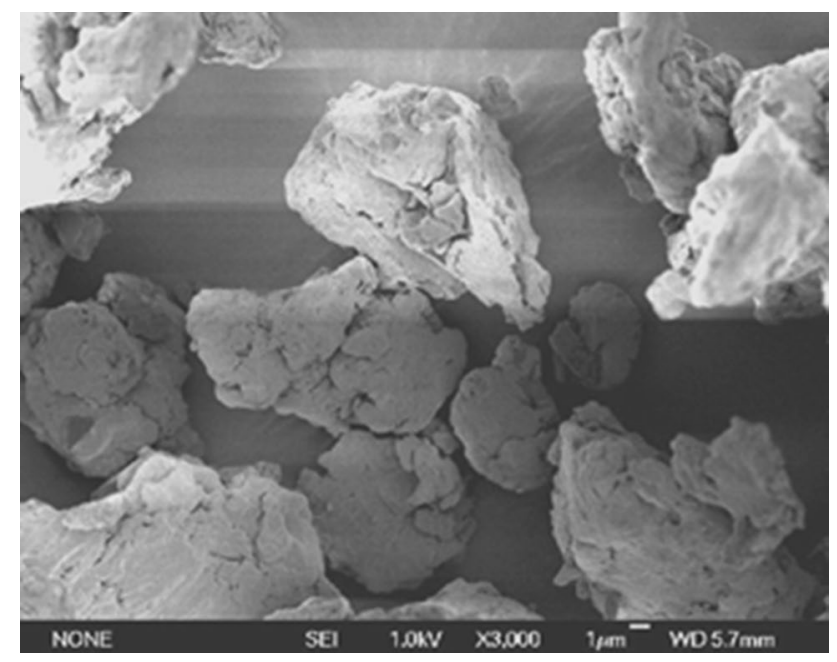

Fig. 8 SEM image for the pure Ni powder milled for $15 \mathrm{~min}$

cold welding, repeated fracture and dynamic recrystallization in the milled samples.

Open Access This article is distributed under the terms of the Creative Commons Attribution 4.0 International License (http://creativecommons.org/licenses/by/4.0/), which permits unrestricted use, distribution, and reproduction in any medium, provided you give appropriate credit to the original author(s) and the source, provide a link to the Creative Commons license, and indicate if changes were made.

\section{References}

1. Koch, C.C., Cavin, O.B., Mckamey, C.G., Scorbrough, J.O.: Preparation of amorphous nickel-niobium (Ni60Nb40) by mechanical alloying. Appl. Phys. Lett. 43(11), 1017-1019 (1983)

2. El-Eskandarany, M.S., Aoki, K., Suniyama, K., Suzuki, K.: Mechanically induced cyclic crystalline-amorphous transformations of ball milled $\mathrm{Co}_{50} \mathrm{Ti}_{50}$ alloy. Scr. Mater. 36, 1001-1009 (1997)

3. Murty, B.S., Ranganathan, S.: Novel materials synthesis by mechanical alloying/milling. Int. Mater. Rev. 43, 101-141 (1998) 
4. Koch, C.C.: Synthesis of nanostructured materials by mechanical milling: problems and opportunities. Nanostruct. Mater. 9(1-8), 13-22 (1997)

5. Zhang, X., Wang, H., Kassem, M., Narayan, J., Koch, C.C.: Preparation of bulk ultrafine-grained and nanostructured $\mathrm{Zn}, \mathrm{Al}$ and their alloys by in situ consolidation of powders during mechanical attrition. Scr. Mater. 46, 661-665 (2002)

6. Zhang, X., Wang, H., Narayan, J., Koch, C.C.: Evidence for the formation mechanism of nanoscale microstructures in cryomilled Zn powder. Acta Mater. 49(8), 1319-1326 (2001)

7. Bor, T.C., Huisman, M.C., Delhez, R., Mittemeijer, E.J.: A method to determine the volume fraction of a separate component in a diffracting volume. Mater. Sci. Forum 278-81, 145-150 (1998)

8. Deb, A.K., Chatterjee, P., Sen Gupta, S.P.: Microstructural characterization of ball-milled $\alpha-\mathrm{Al}_{2} \mathrm{O}_{3}$ : bimodal size distribution and shape anisotropy. J. Appl. Crystallogr. 40, 33-39 (2007)

9. Deb, A.K., Chatterjee, P., Sen Gupta, S.P.: An X-ray diffraction study on dislocation microstructure of as-prepared $\mathrm{Al}-\mathrm{Al}_{2} \mathrm{O}_{3}$ composites. Acta Mater. 52, 2755-2764 (2004)

10. Deb, A.K., Chatterjee, P., Sen Gupta, S.P.: Dependence of U, V, W and other profile shape related parameters on standard Si sample microstructure. Indian J. Phys. 78(7), 539-545 (2004)

11. Thompson, P., Cox, D.E., Hastings, J.B.: Rietveld refinement of Debye-Scherrer synchrotron X-ray data from $\mathrm{Al}_{2} \mathrm{O}_{3}$. J. Appl. Crystallogr. 20, 79-83 (1987)

12. Lutterotti, L.: MAUD Version 2.71. http://maud.radiographema. $\mathrm{com} /$ (2016). Accessed 5 Nov 2017

13. Popa, N.C.: The $(h k l)$ dependence of diffraction-line broadening caused by strain and size for all Laue groups in Rietveld refinement. J. Appl. Crystallogr. 31, 176-180 (1998)

14. Warren, B.E.: X-ray diffraction. Addison-Wesley, Reading (1969)

15. Chatterjee, P., Sen Gupta, S.P.: An X-ray diffraction study of strain localization and anisotropic dislocation contrast in nanocrystalline titanium. Philos. Mag. A 81, 49-60 (2001)

16. Scardi, P., Leoni, M.: Whole powder pattern modelling. Acta Crystallogr. A 58, 190-200 (2002)

17. Williamson, G.K., Smallman, R.E.: Dislocation densities in some annealed and cold-worked metals from measurements on the x-ray Debye-Scherrer spectrum. Philos. Mag. 1(1), 34-46 (1956)

18. Ungar, T., Borbely, A.: The effect of dislocation contrast on x-ray line broadening: a new approach to line profile analysis. Appl. Phys. Lett. 69(21), 3173-3175 (1996)
19. Ungar, T., Revesz, A., Borbely, A.: Dislocations and grain size in electrodeposited nanocrystalline Ni determined by the modified Williamson-Hall and Warren-Averbach procedures. J. Appl. Crystallogr. 31, 554-558 (1998)

20. Ungar, T., Tichy, G.: The effect of dislocation contrast on X-ray line profiles in untextured polycrystals. Phys. Status Solidi 171(2), 425-434 (1999)

21. Ungar, T., Dragomir, I., Revesz, A., Borbely, A.: The contrast factors of dislocations in cubic crystals: the dislocation model of strain anisotropy in practice. J. Appl. Crystallogr. 32(5), 992-1002 (1999)

22. Wilkens, M.: The determination of density and distribution of dislocations in deformed single crystals from broadened X-ray diffraction profiles. Phys. Status Solidi A 2, 359-370 (1970)

23. Wilkens, M.: Theoretical aspects of kinematical X-ray diffraction profiles from crystals containing dislocation distributions. In: Simmons, J.A., de Wit, R., Bullough, R. (eds.) Fundamental Aspects of Dislocation Theory, pp. 1195-1221. NBS Special Publication No. 317 II, US Department of Commerce, Washington DC (1970)

24. Ungar, T., Gubicza, J., Ribarik, G., Borbely, A.: Crystallite size distribution and dislocation structure determined by diffraction profile analysis: principles and practical application to cubic and hexagonal crystals. J. Appl. Crystallogr. 34(3), 298-310 (2001)

25. Ribarik, G., Ungar, T., Gubicza, J.: $M W P$-fit: a program for multiple whole-profile fitting of diffraction peak profiles by ab initio theoretical functions. J. Appl. Crystallogr. 34(5), 669-676 (2001)

26. Borbely, A., Dragomir-Cernatescu, J., Ribarik, G., Ungar, T.: Computer program ANIZC for the calculation of diffraction contrast factors of dislocations in elastically anisotropic cubic, hexagonal and trigonal crystals. J. Appl. Crystallogr. 36, 160-162 (2003)

Publisher's Note Springer Nature remains neutral with regard to jurisdictional claims in published maps and institutional affiliations. 